\title{
Magnetic Properties and Magnetocaloric Effect of $\mathrm{R}_{1-x} \mathrm{R}_{x}^{\prime} \mathrm{Mn}_{2} \mathrm{Ge}_{2}$ Compounds
}

\author{
M. Duraj ${ }^{a}$ And A. SzYTuŁA ${ }^{b}$ \\ ${ }^{a}$ Institute of Physics, Technical University of Cracow, Podchorążych 1, 30-084 Kraków, Poland \\ ${ }^{b}$ M. Smoluchowski Institute of Physics, Jagiellonian University, Reymonta 4, 30-059 Kraków, Poland \\ The magnetic and magnetocaloric properties of $\mathrm{Sm}_{1-x} \mathrm{Gd}_{x} \mathrm{Mn}_{2} \mathrm{Ge}_{2}$ compounds with $0 \leq x \leq 0.10$ have been \\ studied. $\mathrm{SmMn}_{2} \mathrm{Ge}_{2}$ is antiferromagnetic below the Néel temperature $T_{\mathrm{N}}(\approx 400 \mathrm{~K})$. Further cooling leeds to \\ canted ferromagnetic phase below $T_{\mathrm{C}}=341 \mathrm{~K}$. With decreasing temperature, two metamagnetic phase transitions \\ are observed: $\mathrm{F} 2-\mathrm{AF} 1$ at $T_{2}=153 \mathrm{~K}$ and $\mathrm{AF} 1-\mathrm{F} 1$ at $T_{1}=106 \mathrm{~K}$. The maximum values of magnetic entropy \\ change $\left|\Delta S_{\mathrm{m}}\right|$ are found to be $1.5 \mathrm{~J} \mathrm{~K}^{-1} \mathrm{~kg}^{-1}$ at $T_{1}$ and $2.0 \mathrm{~J} \mathrm{~K}^{-1} \mathrm{~kg}^{-1}$ at $T_{2}$ in $\mathrm{SmMn}_{2} \mathrm{Ge}_{2}$. The MCE is found \\ to increase with Gd concentration, $\left|\Delta S_{\mathrm{m}}\left(T_{1}\right)\right|=3.3 \mathrm{~J} \mathrm{~K}^{-1} \mathrm{~kg}^{-1}$, while $\left|\Delta S_{\mathrm{m}}\left(T_{2}\right)\right|$ is slightly enhanced for $x=0.1$. \\ The magnetocaloric effect is found to be positive at $T_{1}$ and negative at $T_{2}$.
}

PACS numbers: $75.30 . \mathrm{Kz}, 75.30 . \mathrm{Sg}$

\section{Introduction}

The term "magnetocaloric effect" (MCE) is generally associated with adiabatic temperature changes or an isothermal entropy change of magnetic material due to the application of a magnetic field. In recent years the MCE have been extensively studied in search for suitable materials applicable for new magnetic refrigeration. For obvious reasons, the magnetic materials that show a large MCE around room temperature and in low magnetic fields are especially desirable. The most important feature of these materials is that they undergo a simultaneous first-order structural and magnetic phase transition, which leads to a giant magnetic entropy change in its ordering temperature.

Up to date, the most useful room temperature magnetic working substances are materials on the basis of rare earth and $3 d$ metals such as: Laves phases $\mathrm{RM}_{2}$ $(\mathrm{R}$ - rare earth, $\mathrm{M}=\mathrm{Al}, \mathrm{Co}, \mathrm{Ni}), \mathrm{Gd}_{5}\left(\mathrm{Si}_{1-x} \mathrm{Ge}_{x}\right)_{4}$, $\operatorname{Mn}\left(\mathrm{As}_{1-x} \mathrm{Sb}_{x}\right), \operatorname{MnFe}\left(\mathrm{P}_{1-x} \mathrm{As}_{x}\right), \mathrm{La}\left(\mathrm{Fe}_{13-x} \mathrm{Si}_{x}\right)$ [1, 2].

The simplest experimental technique to determine $\Delta S_{\mathrm{m}}$ and $\Delta T_{\mathrm{ad}}$ is by magnetization measurements, using the Maxwell relations

$$
\begin{aligned}
& \Delta S_{\mathrm{m}}(T, \Delta H)=\int_{\mathrm{H}_{1}}^{\mathrm{H}_{2}}\left(\frac{\partial M(T, H)}{\partial T}\right)_{\mathrm{H}} \mathrm{d} H, \\
& \Delta T_{\mathrm{ad}}(T, \Delta H) \\
& \quad=-\int_{\mathrm{H}_{1}}^{\mathrm{H}_{2}}\left(\frac{T}{C(T, H)}\right)_{\mathrm{H}}\left(\frac{\partial M(T, H)}{\partial T}\right) \mathrm{d} H .
\end{aligned}
$$

If the temperature derivative of the magnetization is negative, as is the case of regular ferromagnetic materials, the thermodynamic formulation of the $\Delta S_{\mathrm{m}}$ and $\Delta T_{\text {ad }}$ predicts $\Delta S_{\mathrm{m}}<0, \Delta T_{\mathrm{ad}}>0$ (the direct MCE), i.e. the sample heats up when the external magnetic field is applied adiabatically. On the other hand, if the temperature derivative of the magnetization is positive, an opposite effect occurs, i.e. $\Delta S_{\mathrm{m}}>0, \Delta T_{\mathrm{ad}}<0$ (the inverse $\mathrm{MCE}$ ), the sample cools down when the external magnetic field is applied adiabatically [3].

The direct giant MCE appears in $\mathrm{Gd}_{5} \mathrm{Si}_{2} \mathrm{Ge}_{2}$ - this compound undergoes a first-order magneto-structural transition at $276 \mathrm{~K}$, which can be induced not only by changing the temperature, but also by changing the magnetic field or pressure. The inverse MCE exists in different kinds of magnetic arrangements, in antiferromagnetic compounds it is associated with antiparallel disorder of magnetic sublattices [4, 5].

In the case of ternary rare earth intermetallic compounds the observed magnetostructural transition is explained by strong dependence of the exchange constant on interatomic spacing. This magnetostructural coupling complicates the thermodynamics of the system, because it introduces additional mutual dependences between the specific volume and the magnetization. Giant magnetocaloric effect has been observed in $\mathrm{ErRu}_{2} \mathrm{Si}_{2}$ which is associated with field induced metamagnetic transition from antiferromagnetic to ferromagnetic state. The maximum value of entropy change $-\Delta S_{\mathrm{m}}^{\max }$ for the field change of $\Delta H=7 \mathrm{~T}$ are evaluated to be $19.3 \mathrm{~J} /(\mathrm{kg} \mathrm{K})[4]$.

In this work we have studied the magnetocaloric properties deduced from magnetization measurements of $\mathrm{Sm}_{1-x} \mathrm{Gd}_{x} \mathrm{Mn}_{2} \mathrm{Ge}_{2}$ for $x=0$ and $x=0.1$. $\mathrm{R}_{1-x} \mathrm{R}_{x}^{\prime} \mathrm{Mn}_{2} \mathrm{Ge}_{2}$ compounds crystallize in the body centered tetragonal $\mathrm{ThCr}_{2} \mathrm{Si}_{2}$-type structure with the space group $I 4 / \mathrm{mmm}$, which can be described as a stacking of monoatomic layers in the direction of the $c$-axis according the sequence $\mathrm{R}-\mathrm{Ge}-\mathrm{Mn}-\mathrm{Ge}-\mathrm{R}$. These compounds are of particular interest, because both $\mathrm{R}$ and $\mathrm{Mn}$ atoms carry a magnetic moment. The total value of the Mn moment is about $(2.4-3.3) \mu_{\mathrm{B}}$ for the $\mathrm{RMn}_{2} \mathrm{Ge}_{2}$ compounds [6-8].

The high sensitivity of exchange parameters to the intralayer $\mathrm{Mn}-\mathrm{Mn}$ spacing $R_{\mathrm{Mn}-\mathrm{Mn}}^{a}$ (or parameters of 
unit cell) leads to complex and very interesting magnetic phase diagrams of these compounds. The sequence of magnetic phases, which occurs in $\mathrm{SmMn}_{2} \mathrm{Ge}_{2}$, and $\mathrm{Sm}_{1-x} \mathrm{R}_{x}^{\prime} \mathrm{Mn}_{2} \mathrm{Ge}_{2}\left(\mathrm{R}^{\prime}-\mathrm{Gd}, \mathrm{Y}\right)$ compounds is shown in a schematic way in Fig. 1. Types of the magnetic structures are shown in Fig. 2. These structures are described using the notation introduced by Venturini et al. [7]. AFmc (AF1) describes the antiferromagnetic mixed commensurate structure, which is characterised by antiferromagnetic interplane coupling of the in-plane ferromagnetic components and by the commensurate ordering of the antiferromagnetic in-plane components. Fmc (F2) presents the ferromagnetic mixed commensurate structure. $\mathrm{AFl}$ describes the antiferromagnetic layer magnetic structure.

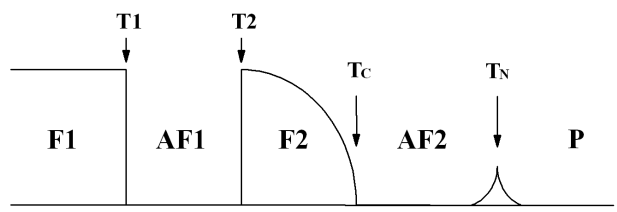

Fig. 1. The magnetic phase sequence for $\mathrm{SmMn}_{2} \mathrm{Ge}_{2}$ and $\mathrm{R}_{1-x} \mathrm{R}_{x}^{\prime} \mathrm{Mn}_{2} \mathrm{Ge}_{2}$ (R, $\mathrm{R}^{\prime}$ - rare earths) compounds. $\mathrm{P}$ - paramagnetic phase, AF2 - antiferromagnetic collinear structure, F2 - canted ferromagnetic structure, AF1 - canted antiferromagnetic structure, F1 reentrant ferromagnetic phase of $\mathrm{Mn}$ and Sm sublattice $[6-9]$.
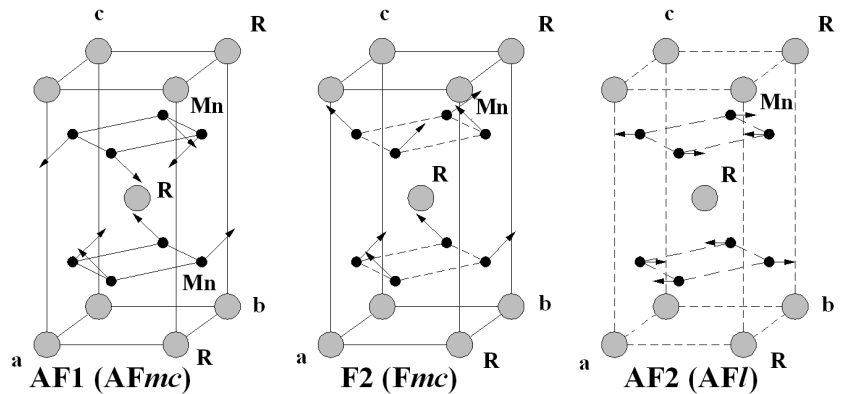

Fig. 2. The magnetic structures of the Mn sublattice in the $\mathrm{R}_{1-x} \mathrm{R}_{x}^{\prime} \mathrm{Mn}_{2} \mathrm{Ge}_{2}$ compounds from neutron diffraction study [7].

The critical lattice spacing criteria, determining the type of magnetic exchange are as follows [6-9]: $R_{\mathrm{Mn}-\mathrm{Mn}}^{a}>0.286 \mathrm{~nm}$, the intralayer in-plane coupling is antiferromagnetic and the interlayer coupling is ferromagnetic, $0.282 \mathrm{~nm}<R_{\mathrm{Mn}-\mathrm{Mn}}^{a}<0.285 \mathrm{~nm}$, intralayer in-plane coupling remains antiferromagnetic but the the interlayer coupling is also antiferromagnetic. The critical value $R_{\mathrm{Mn}-\mathrm{Mn}}^{a}$ for metamagnetic transition $\mathrm{AF}-\mathrm{F}$ is between 0.285 and $0.286 \mathrm{~nm}$.

In $\mathrm{SmMn}_{2} \mathrm{Ge}_{2}, R_{\mathrm{Mn}-\mathrm{Mn}}^{a}=0.287 \mathrm{~nm}$ is slightly larger than critical value at room temperature, so that the compound shows re-entrant ferromagnetism: AF2 phase (between $T_{\mathrm{N}}=385 \mathrm{~K}$ and $T_{\mathrm{C}}=341 \mathrm{~K}$ ), F2 phase (between $T_{\mathrm{C}}=341 \mathrm{~K}$ and $T_{2}=153 \mathrm{~K}$ ), reentrant an- tiferromagnetic AF1 phase (between $T_{2}=153 \mathrm{~K}$ and $T_{1}=106.5 \mathrm{~K}$ ) and reentrant ferromagnetic F1 phase (below $T_{1}=106.5 \mathrm{~K}$ ). The values of the lattice parameters, temperatures of the magnetic phase transitions of $\mathrm{Sm}_{1-x} \mathrm{Gd}_{x} \mathrm{Mn}_{2} \mathrm{Ge}_{2}$ samples are given in Table I [9].

TABLE I

Structural parameters and temperatures of the magnetic phase transitions of $\mathrm{Sm}_{1-x} \mathrm{Gd}_{x} \mathrm{Mn}_{2} \mathrm{Ge}_{2}$ [9].

\begin{tabular}{c|c|c}
\hline \hline & $x=0$ & $x=0.10$ \\
\hline $\mathrm{a}[\mathrm{nm}]$ & $0.4062(5)$ & $0.4058(5)$ \\
$\mathrm{c}[\mathrm{nm}]$ & $1.0895(3)$ & $1.0883(3)$ \\
$c / a$ & 2.681 & 2.682 \\
$V\left[\mathrm{~nm}^{3}\right]$ & $0.1797(4)$ & $0.1792(4)$ \\
$R_{\mathrm{Mn}-\mathrm{Mn}[\mathrm{nm}]}^{a}$ & $0.2872(3)$ & $0.2869(3)$ \\
$T_{1}[\mathrm{~K}]$ & 106.5 & 96 \\
$T_{2}[\mathrm{~K}]$ & 153 & 161 \\
$T_{\mathrm{C}}[\mathrm{K}]$ & 341 & 340
\end{tabular}

\section{Experimental and results}

Magnetic measurements are performed on the polycrystalline samples whose characterizations are reported in Ref. [9]. Magnetization is measured by means of a modified Faraday metod in the temperature range $78-400 \mathrm{~K}$ in the magnetic field up to $1.08 \mathrm{~T}$. The temperature dependence of the magnetization of the $\mathrm{SmMn}_{2} \mathrm{Ge}_{2}$ and $\mathrm{Sm}_{0.9} \mathrm{Gd}_{0.1} \mathrm{Mn}_{2} \mathrm{Ge}_{2}$ compounds is displayed in Fig. 3.

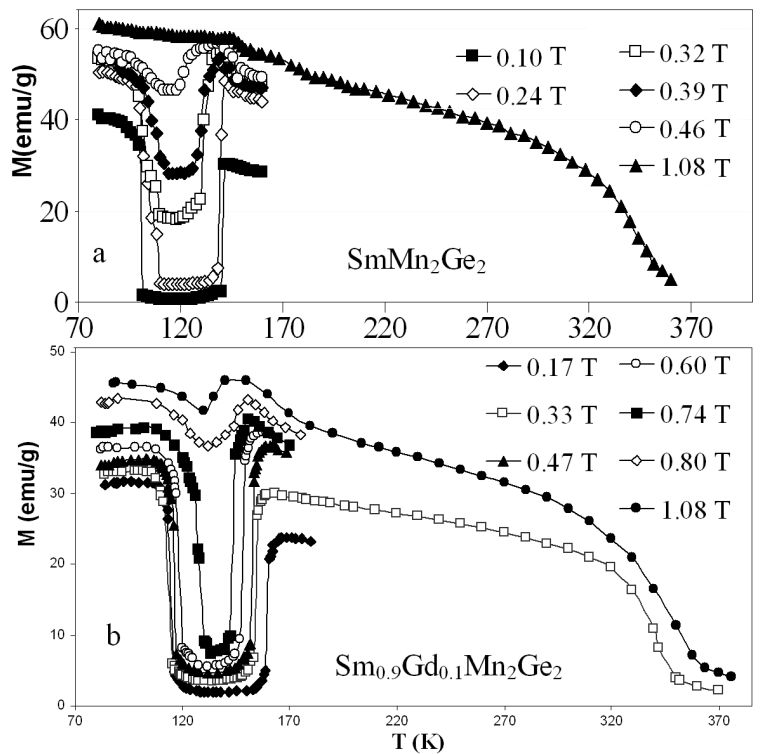

Fig. 3. Temperature dependence of the magnetization of (a) $\mathrm{SmMn}_{2} \mathrm{Ge}_{2}$ and (b) $\mathrm{Sm}_{0.9} \mathrm{Gd}_{0.1} \mathrm{Mn}_{2} \mathrm{Ge}_{2}$ compounds for field change of $0.10-1.08 \mathrm{~T}$ [9].

The crystalline structure is identical for $\mathrm{SmMn}_{2} \mathrm{Ge}_{2}$ and $\mathrm{Sm}_{0.9} \mathrm{Gd}_{0.1} \mathrm{Mn}_{2} \mathrm{Ge}_{2}$ compounds, except the changes 
in the lattice parameters. The decrease in the lattice parameter is attributed to the smaller ionic radius of Gd $(0.1787 \mathrm{~nm})$ compared to that of $\mathrm{Sm}(0.1852 \mathrm{~nm})$. When the value of intralayer Mn-Mn spacing $R_{\mathrm{Mn}-\mathrm{Mn}}^{a}$ approaches the critical value at room temperature, the temperatures of metamagnetic transition AF1-F2 increase.

In this paper, we express the MCE as an isothermal magnetic entropy change $\Delta S_{\mathrm{m}}$, obtained from the magnetization data. The magnetic entropy change $\Delta S_{\mathrm{m}}\left(T_{1}\right)$, $\Delta S_{\mathrm{m}}\left(T_{2}\right)$ was estimated for polycrystalline $\mathrm{SmMn}_{2} \mathrm{Ge}_{2}$, $\mathrm{Sm}_{0.9} \mathrm{Gd}_{0.1} \mathrm{Mn}_{2} \mathrm{Ge}_{2}$ for first-order magnetic phase transition at $T_{1}$ and $T_{2}$.

Based on the Maxwell relation, the isothermal magnetic entropy change is given by relation (1). For discrete fields and temperature intervals, Eq. (1) can be approximated by the following expression:

$$
\Delta S_{\mathrm{m}}(T, \Delta H)=\sum \frac{M_{i+1}-M_{i}}{T_{i+1}-T_{i}} \Delta H_{i},
$$

where $M_{i+1}$ and $M_{i}$ are the magnetization values measured at $T_{i+1}$ and $T_{i}$ respectively, when the magnetic field changed is $\Delta H_{i}$.

Figure 4 (a and b) shows the magnetic entropy change $\Delta S_{\mathrm{m}}$ for $\mathrm{SmMn}_{2} \mathrm{Ge}_{2}$ compound at the vicinity of $T_{1}$ and $T_{2}$, respectively. It can be seen that the entropy change is negative (positive MCE) for the metamagnetic phase transition $\mathrm{F} 1-\mathrm{AF} 1$ at $T_{1}=106.5$. The maximum value of entropy change is equal to $\left|\Delta S_{\mathrm{m}}\left(T_{1}\right)\right|=1.5 \mathrm{~J} \mathrm{~K}^{-1} \mathrm{~kg}^{-1}$.

A particularly interesting feature (common to all the $\mathrm{SmMn}_{2} \mathrm{Ge}_{2}$-like compounds) is the positive entropy change (negative MCE) at temperature $T_{2}=153 \mathrm{~K}$. The magnetic phase transition AF1-F2 at temperature $T_{2}$ is connected with the ordering at $\mathrm{Mn}$ sublattice. The interlayer $\mathrm{Mn}-\mathrm{Mn}$ exchange interaction changes the sign from negative to positive as the interatomic distance $R_{\mathrm{Mn}-\mathrm{Mn}}^{a}$ exceeds critical value at $T_{2}$. We estimated $\left|\Delta S_{\mathrm{m}}\left(T_{2}\right)\right|=2.0 \mathrm{~J} \mathrm{~K}^{-1} \mathrm{~kg}^{-1}$ for AF1-F2 phase transition at $T_{2}$.

When substituting Gd partially for $\mathrm{Sm}$ (for $0 \leq x \leq$ 0.10 ) it is found that the temperature dependence of magnetization behavior is nearly the same as in $\mathrm{SmMn}_{2} \mathrm{Ge}_{2}$ (Fig. 3). The lattice parameters decrease with increasing $x$ and for $\mathrm{Sm}_{0.9} \mathrm{Gd}_{0.1} \mathrm{Mn}_{2} \mathrm{Ge}_{2}$ the interatomic distance is equal to $R_{\mathrm{Mn}-\mathrm{Mn}}^{a}=0.2869 \mathrm{~nm}$ at room temperature. With an increase in $\mathrm{Gd}$ content the range of antiferromagnetic order AF1 (AFmc) increases. For $x=0.10$ the metamagnetic phase transition AF1-F2 occurs at temperature $T_{2}=161 \mathrm{~K}$ and for the same intralayer $\mathrm{Mn}-\mathrm{Mn}$ spacing $R_{\mathrm{Mn}-\mathrm{Mn}}^{a} \approx 0.286 \mathrm{~nm}$ being critical distance. The same effect was observed when applying hydrostatic pressure for $\mathrm{SmMn}_{2} \mathrm{Ge}_{2}$ [9-11].

Figure 5 shows the magnetic entropy change $\Delta S_{\mathrm{m}}$ at the first-order magnetic phase transitions for $\mathrm{Sm}_{0.9} \mathrm{Gd}_{0.1} \mathrm{Mn}_{2} \mathrm{Ge}_{2}$. For the magnetic phase transition $\mathrm{F} 1-\mathrm{AF} 1$ at $T_{1}=96 \mathrm{~K}$ we estimated $\left|\Delta S_{\mathrm{m}}\left(T_{1}\right)\right|=$ $3.3 \mathrm{~J} \mathrm{~K}^{-1} \mathrm{~kg}^{-1}$ and the entropy change is negative (positive MCE). With increasing Gd content the value of entropy change increases at $T_{1}$.

At $T_{2}=161 \mathrm{~K}$, the magnetic state transforms from

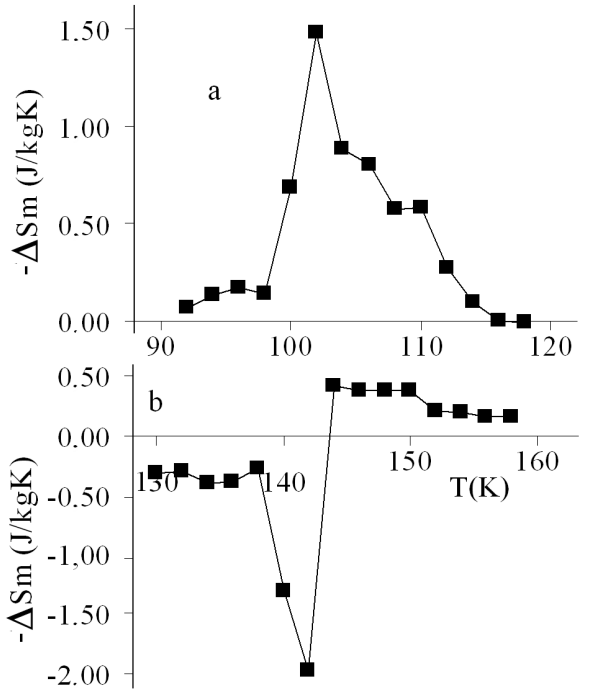

Fig. 4. Magnetic entropy change $\Delta S_{\mathrm{m}}$ in magnetic field change of $0.10-1.08 \mathrm{~T}$ for $\mathrm{SmMn}_{2} \mathrm{Ge}_{2}$ compound at the vicinity of the (a) F1-AF1 and (b) AF1-F2 magnetic phase transitions.

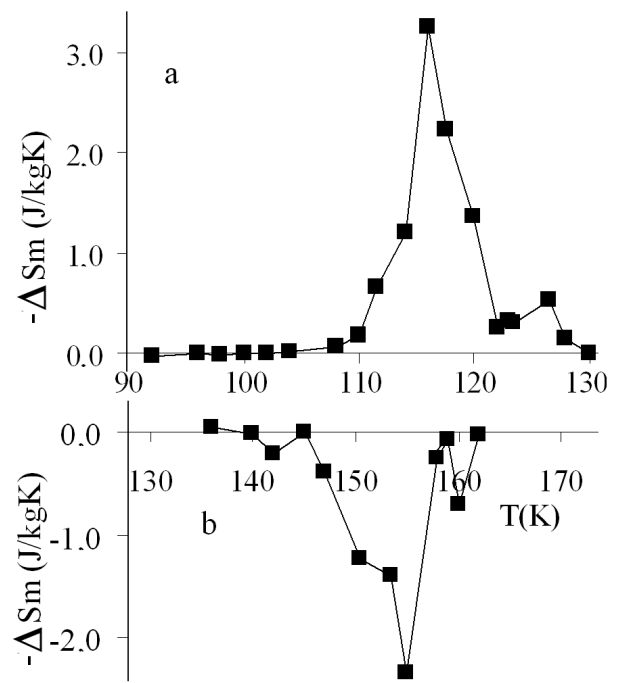

Fig. 5. Magnetic entropy change $\Delta S_{\mathrm{m}}$ in magnetic field change of $0.17-1.08 \mathrm{~T}$ for $\mathrm{Sm}_{0.9} \mathrm{Gd}_{0.1} \mathrm{Mn}_{2} \mathrm{Ge}_{2}$ compound at the vicinity of the (a) F1-AF1 and (b) AF1-F2 magnetic phase transitions.

AF1 to the F2 state, and the positive entropy change (negative MCE) was observed. The maximum value of entropy change $\left|\Delta S_{\mathrm{m}}\left(T_{2}\right)\right|$ is $2.3 \mathrm{~J} \mathrm{~K}^{-1} \mathrm{~kg}^{-1}$ and varies slightly with $x$. This indicates that the contribution to the magnetic entropy change at high temperatures is mainly connected with Mn sublattice.

\section{Discussion}

The results of $\left|\Delta S_{\mathrm{m}}\left(T_{1}\right)\right|$ and $\left|S_{\mathrm{m}}\left(T_{2}\right)\right|$ obtained in this work can be compared to the value determined from 
Clausius-Clapeyron equation [9]:

$$
\frac{\mathrm{d} T_{\mathrm{F}-\mathrm{AF}}}{\mathrm{d} p}=\frac{\Delta V}{\Delta S} .
$$

The values of $\mathrm{d} T_{1} / \mathrm{d} P$ and $\mathrm{d} T_{2} / \mathrm{d} P$ were determined from pressure dependence of $T_{1}$ and $T_{2}$ temperatures [9-11]. The changes of the unit cell volume at the temperature phase transitions $T_{1}$ and $T_{2}$ are $\Delta V / V \approx 0.25 \%$ and $\approx 0.30 \%$, respectively. Data are given in Table II [9-11].

TABLE II

Thermodynamic parameters of the first-order phase transition of $\mathrm{Sm}_{1-x} \mathrm{Gd}_{x} \mathrm{Mn}_{2} \mathrm{Ge}_{2}$ [9-11].

\begin{tabular}{c|c|c}
\hline \hline & $x=0$ & $x=0.10$ \\
\hline$T_{1}[\mathrm{~K}]$ & 106.5 & 96 \\
$T_{2}[\mathrm{~K}]$ & 153 & 161 \\
$\mathrm{~d} T_{1} / \mathrm{d} P[\mathrm{~K} / \mathrm{GPa}]$ & $-(170 \pm 20)$ & $-(100 \pm 20)$ \\
$\mathrm{d} T_{2} / \mathrm{d} P[\mathrm{~K} / \mathrm{GPa}]$ & $+(171 \pm 20)$ & $+(188 \pm 20)$ \\
$P_{\text {cr }}[\mathrm{GPa}]$ & $1.00 \pm 0.05$ & $0.92 \pm 0.05$ \\
$T_{\text {cr }}[\mathrm{K}]$ & $332 \pm 2$ & $330 \pm 2$
\end{tabular}

The values of $\Delta S_{\mathrm{m}}$ calculated on the basis of ClausiusClapeyron equation and using the Maxwell relations are listed in Table III.

\section{TABLE III}

$\Delta S_{\mathrm{m}}$ at the first-order phase transitions of $\mathrm{Sm}_{1-x} \mathrm{Gd}_{x} \mathrm{Mn}_{2} \mathrm{Ge}_{2}$.

\begin{tabular}{l|c|c|c|c}
\hline \hline & \multicolumn{2}{|c|}{$\begin{array}{c}\Delta S_{\mathrm{m}}\left[\mathrm{J} \mathrm{K}^{-1} \mathrm{~kg}^{-1}\right] \\
\text { from Maxwell } \\
\text { relations }\end{array}$} & \multicolumn{2}{|c|}{$\begin{array}{c}\Delta S_{\mathrm{m}}\left[\mathrm{J} \mathrm{K}^{-1} \mathrm{~kg}^{-1}\right] \\
\text { from Clausius- } \\
\text { Clapeyron equation }\end{array}$} \\
\hline & $T_{1}$ & $T_{2}$ & $T_{1}$ & $T_{2}$ \\
$\mathrm{SmMn}_{2} \mathrm{Ge}_{2}$ & -1.5 & 2.0 & -2.4 & 2.6 \\
$\mathrm{Sm}_{0.9} \mathrm{Gd}_{0.1} \mathrm{Mn}_{2} \mathrm{Ge}_{2}$ & -3.3 & 2.3 & -3.3 & 3.0
\end{tabular}

These values are comparable, and much smaller than $R \ln 2$ for a simple spin state $(S=1 / 2)$ or $R \ln 6$ for a $\mathrm{Sm}$ moment $(J=5 / 2)$.

We estimated $\left|\Delta S_{\mathrm{m}}\left(T_{1}\right)\right|=1.5 \mathrm{~J} \mathrm{~K}^{-1} \mathrm{~kg}^{-1}$ for the F1-AF1 phase transition at $T_{1}$. This value is similar to the data $\left|\Delta S_{\mathrm{m}}\left(T_{1}\right)\right|=1.4 \mathrm{~J} \mathrm{~K}^{-1} \mathrm{~kg}^{-1}[12]$ and $\left|\Delta S_{\mathrm{m}}\left(T_{1}\right)\right|=1.6 \mathrm{~J} \mathrm{~K}^{-1} \mathrm{~kg}^{-1}[13]$. The sign of $\left|\Delta S_{\mathrm{m}}\left(T_{1}\right)\right|$ is negative, suggesting that an applied magnetic field reduced the magnetic entropy in the AF1 phase. This fact is due to magnetic phase transition from an order state to a disorder state on the Sm sublattice and change of magnetic order in Mn sublattice. At the magnetic phase transition temperature $T_{2}$, the value of $\left|\Delta S_{\mathrm{m}}\left(T_{2}\right)\right|=2.0 \mathrm{~J} \mathrm{~K}^{-1} \mathrm{~kg}^{-1}$ is positive and greater than $1.3 \mathrm{~J} \mathrm{~K}^{-1} \mathrm{~kg}^{-1}$ in Ref. [12].

The entropy change estimated for $\mathrm{Sm}_{0.9} \mathrm{Gd}_{0.1} \mathrm{Mn}_{2} \mathrm{Ge}_{2}$ at $T_{1}$ is $\left|\Delta S_{\mathrm{m}}\left(T_{1}\right)\right|=3.3 \mathrm{~J} \mathrm{~K}^{-1} \mathrm{~kg}^{-1}$. A similar increase in the MCE has been observed in $\mathrm{Gd}_{1-x} \mathrm{Sm}_{x} \mathrm{Mn}_{2} \mathrm{Ge}_{2}$ with an increase in Gd content [14, 15].
In order to obtain the information about magnetic states of $\mathrm{SmMn}_{2} \mathrm{Ge}_{2}$ the pressure effect on MCE was discussed in [13]. $\left|\Delta S_{\mathrm{m}}\left(T_{1}\right)\right|$ increases from $1.2 \mathrm{~J} \mathrm{~K}^{-1} \mathrm{~kg}^{-1}$ at the atmospheric pressure to $4.92 \mathrm{~J} \mathrm{~K}^{-1} \mathrm{~kg}^{-1}$ for $P=0.5 \mathrm{GPa}$. Basing on the experimentally obtained $(P, T)$ magnetic phase diagrams $[9-11,16]$, values of critical temperature $T_{\text {cr }}$ and the critical pressure $P_{\text {cr }}$ (i.e. the Fmc phase disappears) were obtained (Table II). From these results the relative change of the unit cell volume as function of external pressure was estimated to be $\Delta V=\kappa P$, where $\kappa=-3.8 \times 10^{-3} \mathrm{~nm}^{3} / \mathrm{GPa}$. An increase in Gd content $x=0.10$ is equivalent to the hydrostatic pressure $P \approx 0.14 \mathrm{GPa}$. The magnetocalorical effect is found to increase with Gd concentration (or with hydrostatic pressure) at $T_{1}$. The MCE associated with the Mn sublattice at $T_{2}$ is slightly enhanced.

\section{References}

[1] K.A. Gschneidner, Jr., V.K. Pecharski, A.O. Tsokol, Rep. Prog. Phys. 68, 1479 (2005).

[2] A.M. Tishin, J. Magn. Magn. Mater. 316, 351 (2007).

[3] P.J. von Ranke, N.A. de Oliveira, B.P. Alho, E.J.R. Plaza, V.S.R. de Sousa, L. Caron, M.S. Reis, J. Phys., Condens. Matter 21, 056004 (2009).

[4] T. Samanta, I. Das, S. Banerjee, Appl. Phys. Lett. 91, 152506 (2007).

[5] V.K. Pecharski, K.A. Gschneidner Jr., Adv. Mater. 13, 683 (2001).

[6] A. Szytuła, in: Handbook of Magnetic Materials, Eds. K.H.J. Bushow, Vol. 6, Elsevier, Amsterdam 1991, p. 85 .

[7] G. Venturini, R. Welter, E. Ressouche, B. Malaman, J. Alloys Comp. 223, 101 (1995).

[8] I. Dincer, Y. Elerman, A. Elmali, H. Ehrenberg, G. Andre, J. Magn. Magn. Mater. 313, 342 (2007).

[9] M. Duraj, Monografia 213, Politechnika Krakowska, Kraków 1997.

[10] M. Duraj, R. Duraj, A. Szytuła, Z. Tomkowicz, J. Magn. Magn. Mater. 73, 240 (1988).

[11] M. Duraj, R. Duraj, A. Szytuła, J. Magn. Magn. Mater. 79, 61 (1989).

[12] K. Koyama, S. Miura, H. Okada, T. Shigeoka, S. Fujieda, A. Fujita, K. Fukamichi, K. Watanabe, J. Alloys. Comp. 118, 408 (2006).

[13] K. Koyama, S. Miura, H. Okada, T. Shigeoka, K. Watanabe, Mater. Trans., 48, 451 (2007).

[14] P. Kumar, N. Singh, A. Nigam, S. Malik, J. Phys. Condens. Matter 19, 386210 (2007).

[15] M. Duraj, A. Szytuła, The European Conference Physics of Magnetism Abstract Book, Poznań 2008, P-3-19, p. 93.

[16] T. Kaneko, T. Kanomata, H. Yasui, T. Shigeoka, M. Iwata, Y. Nakagawa, J. Phys. Soc. Jpn. 61, 4164 (1992). 